\title{
Unusual Indolent Course of a Chronic Active Epstein-Barr Virus-Associated Natural Killer Cell Lymphoproliferative Disorder
}

Arwa Z. Al-Riyami, ${ }^{1}$ "Khalil Al-Farsi, ${ }^{1}$ Murtadha Al-Khabori, ${ }^{1}$ Mohammed Al-Huneini, ${ }^{1}$ Ibrahim Al-Hadabbi ${ }^{2}$

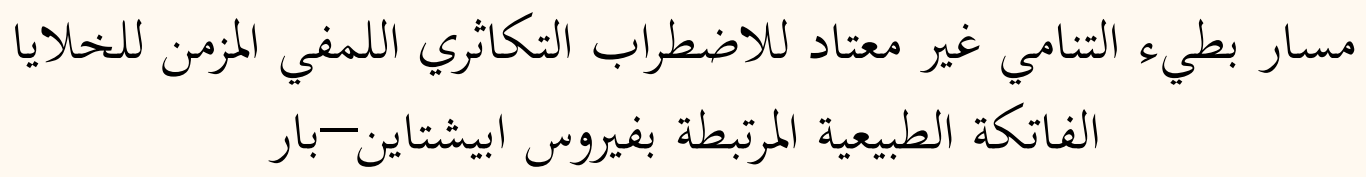

أروى الريامي، خليل الفارسي، مرتضى الخابوري، محمد الحنيني، إبراهيم الهدابي

ABSTRAC T: Natural killer (NK) cell lymphoproliferative disorders are uncommon and the Epstein-Barr virus (EBV) plays an important aetiological role in their pathogenesis. We report a 20 -year-old male with a chronic active EBV infection associated with a NK cell lymphoproliferative disorder which had an unusual indolent course. He presented to the Sultan Qaboos University Hospital in Muscat, Oman, in December 2011 with a history of intermittent fever and coughing. Examinations revealed generalised lymphadenopathy, hepatosplenomegaly, leukocytosis, transaminitis, diffuse bilateral lung infiltrates and bone marrow lymphocyte involvement. A polymerase chain reaction (PCR) test revealed a high EBV viral load in the peripheral blood cells. The patient received a course of piperacillin-tazobactam for Klebsiella pneumoniae, but no active treatment for the lymphoproliferative disorder. However, his lymphocyte count, serum lactate dehydrogenase and liver enzymes dropped spontaneously. In addition, EBV PCR copies fluctuated and then decreased significantly. He remained clinically asymptomatic over the following four years.

Keywords: Epstein-Barr Virus Infections; Natural Killer Cell; Lymphoproliferative Disorders; Spontaneous Remission; Case Report; Oman.

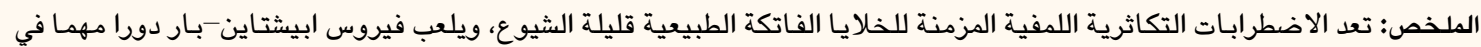

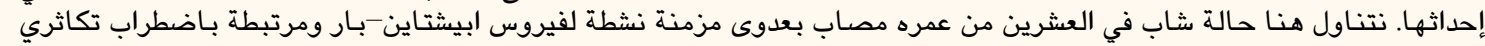

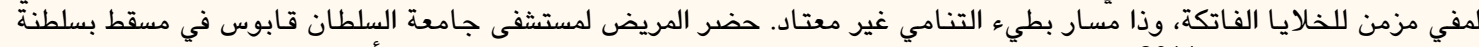

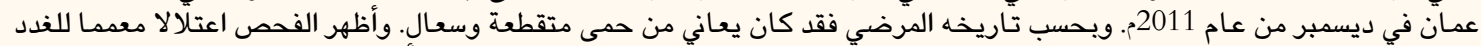

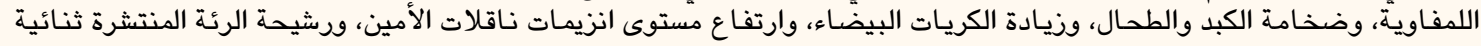

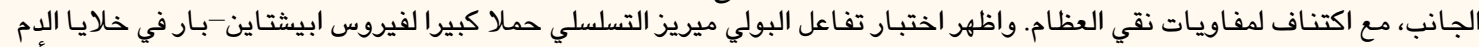

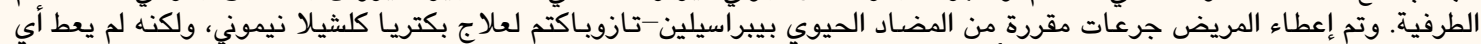

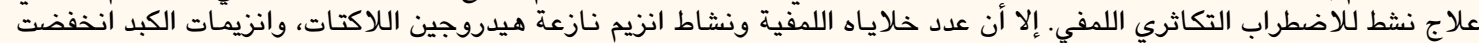

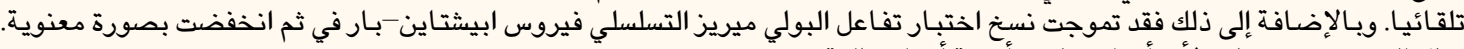
وظل المريض غير مظهر لألي أعراض لمدة أرس أربعة أعوام تالية.

كلمات مفتاحية: حمى عدوى فيروس ابيشتاين-بار؛ الخلية الفاتكة الطبيعية؛ الاضطرابات التكاثرية اللمفية؛ التعافي التلقائي؛ عرض حالة؛ عمان.

$\mathrm{E}$ PSTEIN-BARR VIRUs (EBV)-ASSOCIATED T/ natural killer (NK) cell lymphoproliferative disease is a systemic illness characterised by the clonal proliferation of EBV-infected T or NK cells. ${ }^{1-4}$ Different clinical entities include chronic active EBV (CAEBV) infections, EBV-associated haemophagocytic lymphohistiocytosis, severe mosquito bite allergies and hydroa vacciniforme. Although EBVassociated T/NK cell lymphoproliferative disorders are primarily found among paediatric patients, several reports of adult cases have been published. ${ }^{1,5,6}$ There is a strong racial predisposition for CAEBV infections; most cases are described in Japan and Korea with predominance of the T/NK cell type, while some have been reported in native populations from Mexico, Peru and Central America. ${ }^{5-8}$ In contrast, CAEBV infections are rare among Caucasians and AfricanAmericans. ${ }^{2}$ However, AB cell type CAEBV has been mainly observed in Western countries while the prevalence in other racial groups is unknown., ${ }^{2,5-8}$

Originally, CAEBV of the T/NK type was referred to as chronic or recurrent infectious mononucleosislike syndrome. ${ }^{9}$ Clinical manifestations observed among patients with the severe form of the disease are variable and appear to be more aggressive in adult patients compared to those with childhood- 
onset disease. ${ }^{6}$ Clinical features include fever, liver dysfunction, splenomegaly, lymphadenopathies and cytopaenia, with these being seen more commonly in T cell cases. ${ }^{1}$ This report describes a patient with EBVassociated NK cell lymphoproliferative disease from Oman with an unusual indolent chronic course that did not require any therapeutic intervention; to the best of the authors' knowledge, this is the first case of this kind reported from the Middle East.

\section{Case Report}

A 20-year-old previously healthy male presented to the Sultan Qaboos University Hospital, Muscat, Oman, in December 2011 with a six-month history of intermittent fever and a recent history of coughing. He had not lost any weight, did not suffer from night sweats and his family history was unremarkable. He had no symptoms suggestive of an underlying autoimmune disorder or a connective tissue disease. Physical examination revealed bilateral non-bulky submandibular lymph nodes without skin lesions. The rest of the examination was unremarkable. Abdominal ultrasonography showed mild hepatosplenomegaly with normal echogenicity and no focal lesions. A complete blood count revealed leukocytosis (total white cell count: $46.2 \times 10^{9} / \mathrm{L}$; normal range [NR]: 2.2-10.0 x 109/L) and lymphocytosis (lymphocyte count: $37.3 \times 10^{9} / \mathrm{L}$; NR: $\left.1.2-4.0 \times 10^{9} / \mathrm{L}\right)$. The patient had normal haemoglobin levels $(12.2 \mathrm{~g} / \mathrm{dL}$; NR: $11.5-15.5 \mathrm{~g} / \mathrm{dL}$ ) and a normal platelet count (351.0 x 10\%/L; NR: $\left.140.0-400.0 \times 10^{9} / \mathrm{L}\right)$. A blood smear showed lymphocytosis with monomorphic large granular lymphocytes. Flow cytometry revealed $82 \%$ lymphocytes, of which $90 \%$ were NK cells. These were positive for cluster of differentiation (CD) 16, partial CD56, CD2, CD7, human leukocyte antigen-D related and CD38 cells and negative for surface CD3 and CD5 cells and T cell receptors $\alpha / \beta$ and $\gamma / \delta$. Approximately 25-30\% of the CD56-positive cells were homogenously positive for CD8 ${ }^{\mathrm{dim}}$. A bone marrow aspirate showed $33 \%$ granular lymphocytes and flow cytometry findings similar to those of the peripheral blood cells. Moreover, the bone marrow biopsy showed interstitial infiltrate of CD8 and granzyme B-positive small lymphocytes. An EBV polymerase chain reaction (PCR) test revealed a high viral load $(116,750$ copies $/ \mathrm{mL})$. A trephine biopsy was positive for EBV by in situ hybridisation. Consequently, the diagnosis of an EBV-associated NK cell lymphoproliferative disorder was made.

Laboratory investigations revealed high lactate dehydrogenase (LDH; 406 U/L; NR: 135-225 U/L), aspartate aminotransferase (74 IU/L; NR: 0-38 IU/L), alanine transaminase (91 IU/L; NR: 0-41 IU/L), alkaline phosphatase (225 IU/L; NR: 40-129 IU/L), indirect hyperbilirubinemia (total bilirubin: $25 \mu \mathrm{mol} / \mathrm{L}$; NR: 0-17 $\mu \mathrm{mol} / \mathrm{L})$ and C-reactive protein $(22 \mathrm{mg} / \mathrm{L}$; NR: 0-8 mg/L) levels. Serum calcium, uric acid, potassium, phosphate and creatinine levels were normal. Serology for hepatitis B and C and human immunodeficiency virus was negative. Karyotype testing showed normal results. A chest X-ray showed bilateral prominent reticulonodular changes and left hilar prominence. Contrast-enhanced computed tomography (CT) of the neck, chest and abdomen revealed small subcentimetre-sized lymph nodes in the bilateral jugulodigastric, pretracheal, axillary and mesenteric areas, as well as slightly enlarged hilar lymph nodes. In addition, bilateral small ill-defined nodular pulmonary densities were observed. Sputum cultures grew Klebsiella pneumoniae; however, bronchoalveolar lavage was negative for microorganisms including Mycobacterium tuberculosis, fungi and Pneumocystis carinii. A transbronchial biopsy revealed an interalveolar infiltrate of granzyme B- and EBV-positive lymphocytes. No reactive follicles or granulomata were present.

While a course of piperacillin/tazobactam was prescribed to treat the bacterial pneumonia, the patient declined any active therapy for his underlying lymphoproliferative disorder. He was closely monitored and a spontaneous gradual drop was observed in his lymphocyte count, serum LDH levels and liver enzymes over the following 12 months. Additionally, EBV PCR copies fluctuated and then decreased significantly [Figure 1]. The patient's symptoms resolved over a period of two months and he remained clinically asymptomatic with a gradually decreasing lymphocyte count $\left(4.0 \times 10^{9} / \mathrm{L}\right)$ with large granular lymphocyte morphology. His serum LDH levels remained normal and a repeat CT scan showed stable subcentimetre lymphadenopathy in the cervical, pretracheal and hilar areas, along with mild hepatosplenomegaly. The patient remained clinically well over the four years following his initial diagnosis.

\section{Discussion}

In general, patients with EBV-associated NK cell lymphoproliferative disease exhibit large granular lymphocytosis, hypersensitivity to mosquito bites, skin rashes, defective NK cell activity and high immunoglobulin E levels., The diagnostic criteria for this disease entity was first proposed by Okano et al. in the absence of apparent features of a known 


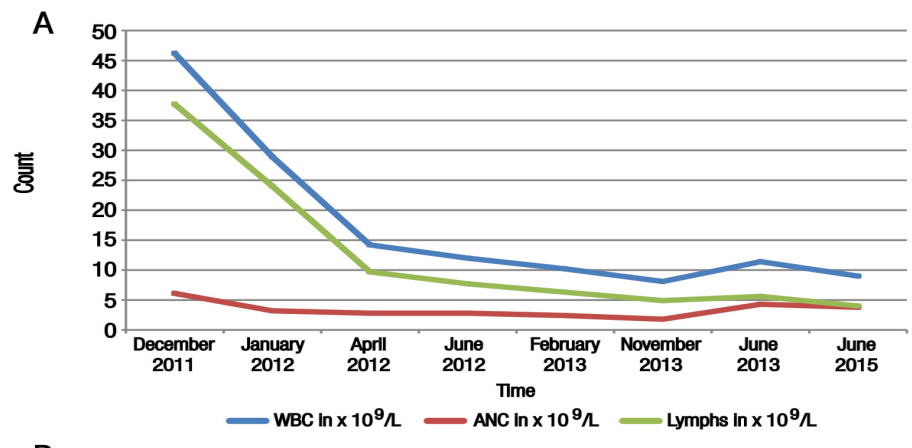

B
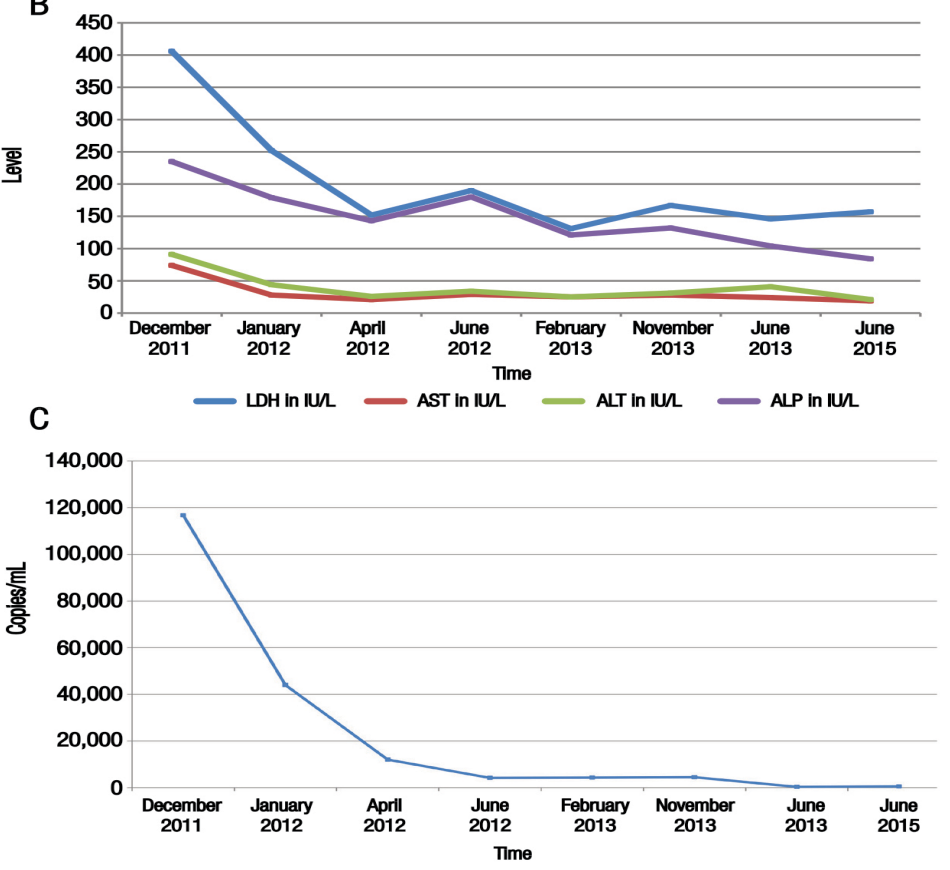

Figure 1A-C: Graphs showing the significant drop over time in (A) total white cell count, (B) liver enzyme levels and (C) Epstein-Barr viral load in a 20-year-old male with an unusual indolent course of chronic active Epstein-Barr virusassociated natural killer cell lymphoproliferative disorder. The patient declined to undergo any active therapy for the disorder and seemed to exhibit a spontaneous recovery.

WBC = white blood cell count; $A N C=$ absolute neutrophil count Lymphs = lymphocyte count; $L D H=$ lactate dehydrogenase H; $A S T=$ aspartate aminotransferase; $A L T$ = alanine transaminase; $A L P=$ alkaline phosphatase.

underlying disease at the time of diagnosis. ${ }^{10}$ The patient in the current case displayed morphology similar to patients with the $\mathrm{T}$ cell subtype and an immunophenotype of the NK variant. He did not undergo testing for NK cell killing activity; however, he fulfilled the criteria proposed by Okano et al., including persistent infectious mononucleosis-like symptoms, unusual patterns of anti-EBV antibodies, increased EBV genome in affected tissues (including peripheral blood cells) and chronic illness unexplained by other known disease processes. ${ }^{10}$

The clinical outcome for patients with CAEBV infections is reportedly poor and appears to be worse for $\mathrm{CD}^{+}{ }^{+} \mathrm{T}$ cell cases than NK cell cases. ${ }^{1}$ CAEBV often results in life-threatening complications such as haemophagocytic syndrome, disseminated intravascular coagulopathy, hepatic failure, digestive tract ulceration/proliferation, coronary artery aneurysms, central nervous system involvement, myocarditis and interstitial pneumonia. ${ }^{11}$ In addition, these patients respond poorly to chemotherapy and have a high risk of eventual progression to overt leukaemia and lymphomas in the form of extranodal NK/T cell lymphomas of nasal type (ENKLs), aggressive NK cell leukaemia (ANKL) and peripheral $\mathrm{T}$ cell leukaemia or lymphomas. ${ }^{1,11,12}$ Some researchers recommend an early bone marrow transplant while the patient is in good general health, despite the associated transplant-related mortality. ${ }^{1}$ Further research is required to assess the actual prevalence of EBVassociated T/NK lymphoproliferative disorders and improve patient outcomes.

Poor prognostic features which indicate early intervention include advanced age at onset (over eight 
years old), the presence of thrombocytopaenia (platelet count: <120,000/L) and T cell (rather than NK cell) associated disease. ${ }^{13}$ The overall outcome of NK cellassociated disease is variable. There are reports of some patients who eventually developed ENKL and ANKL while other cases seem to have indolent courses. ${ }^{1}$ Two indolent cases reportedly achieved complete remission with oral acyclovir therapy and weekly intravenous cytarabine administration; however, the role of these agents in achieving complete remission is not clear. ${ }^{1}$ In the current case, the patient appeared to exhibit an indolent course despite persistent lymphocytosis, generalised lymphadenopathy, initial multi-organ involvement (including lung involvement) and poor prognostic indicators.

\section{Conclusion}

EBV-associated T/NK lymphoproliferative disorders are uncommonly seen outside of Japan, Korea and Taiwan and are often aggressive. To the best of the authors' knowledge, the patient in this report represents the first case from the Middle East with an unusual indolent course which resolved spontaneously without therapeutic intervention.

\section{References}

1. Kimura H, Ito Y, Kawabe S, Gotoh K, Takahashi Y, Kojima S et al. EBV-associated T/NK-cell lymphoproliferative diseases in nonimmunocompromised hosts: Prospective analysis of 108 cases. Blood 2012; 119:673-86. doi: 10.1182/blood-201110-381921.

2. Cohen JI, Kimura H, Nakamura S, Ko YH, Jaffe ES. EpsteinBarr virus-associated lymphoproliferative disease in nonimmunocompromised hosts: A status report and summary of an international meeting, 8-9 September 2008. Ann Oncol 2009; 20:1472-82. doi: 10.1093/annonc/mdp064.
3. Kikuta H, Taguchi Y, Tomizawa K, Kojima K, Kawamura N, Ishizaka $\mathrm{A}$, et al. Epstein-Barr virus genome-positive $\mathrm{T}$ lymphocytes in a boy with chronic active EBV infection associated with Kawasaki-like disease. Nature 1988; 333:455-7. doi: $10.1038 / 333455 \mathrm{a} 0$

4. Kawa-Ha K, Ishihara S, Ninomiya T, Yumura-Yagi K, Hara J, Murayama F, et al. CD3- negative lymphoproliferative disease of granular lymphocytes containing Epstein-Barr viral DNA. J Clin Invest 1989; 84:51-5. doi: 10.1172/JCI114168.

5. Isobe $\mathrm{Y}$, Aritaka N, Setoguchi Y, Ito Y, Kimura H, Hamano Y, et al. T/NK cell type chronic active Epstein-Barr virus disease in adults: An underlying condition for Epstein-Barr virusassociated T/NK-cell lymphoma. J Clin Pathol 2012; 65:278-82. doi: 10.1136/jclinpath-2011-200523.

6. Arai A, Imadome K, Watanabe Y, Yoshimori M, Koyama T, Kawaguchi T, et al. Clinical features of adult-onset chronic active Epstein-Barr virus infection: A retrospective analysis. Int J Hematol 2011; 93:602-9. doi: 10.1007/s12185-011-0831-x.

7. Cohen JI, Jaffe ES, Dale JK, Pittaluga S, Heslop HE, Rooney CM, et al. Characterization and treatment of chronic active EpsteinBarr virus disease: A 28-year experience in the United States. Blood 2011; 117:5835-49. doi: 10.1182/blood-2010-11-316745.

8. Kimura H, Hoshino Y, Kanegane H, Tsuge I, Okamura T, Kawa K, et al. Clinical and virologic characteristics of chronic active Epstein-Barr virus infection. Blood 2001; 98:280-6. doi: 10.1182/blood.V98.2.280

9. Straus SE. The chronic mononucleosis syndrome. J Infect Dis 1988; 157:405-12. doi: 10.1093/infdis/157.3.405.

10. Okano M, Kawa K, Kimura H, Yachie A, Wakiguchi H, Maeda A, et al. Proposed guidelines for diagnosing chronic active EpsteinBarr virus infection. Am J Hematol 2005; 80:64-9. doi: 10.1002/ ajh.20398.

11. Kimura H. Pathogenesis of chronic active Epstein-Barr virus infection: Is this an infectious disease, lymphoproliferative disorder, or immunodeficiency? Rev Med Virol 2006; 16:251-61. doi: 10.1002/rmv.505.

12. Imashuku S, Teramura T, Tauchi H, Ishida Y, Otoh Y, Sawada M, et al. Longitudinal follow-up of patients with Epstein-Barr virusassociated hemophagocytic lymphohistiocytosis. Haematologica 2004; 89:183-8.

13. Kimura H, Morishima T, Kanegane H, Ohga S, Hoshino Y, Maeda A, et al. Prognostic factors for chronic active EpsteinBarr virus infection. J Infect Dis 2003; 187:527-33. doi: 10.1086 /367988. 